\title{
A LUDICIDADE DA CAPOEIRA EM PROL DO LAZER ATIVO DENTRO DA EDUCAÇÃO ESCOLAR
}

\author{
${ }^{1}$ Reginaldo Neves Martins
}

\section{RESUMO}

A ludicidade da capoeira em prol do lazer ativo dentro da educação escolar tem por objetivo realizar uma demonstração das consequências do lazer passivo exercitado pelos educando em idade escolar e a prática da capoeira como instrumento de ensino-aprendizagem em virtude de uma metodologia ativa em que o sujeito do processo possa sentir participante de sua própria história formativa e construtora de uma ação social de maneira proativa. Sendo que discute a prática do lazer ativo em contravenção ao lazer passivo que segrega os sujeitos em estudos limitando suas relações sociais.

Palavras-chave: Lazer. Aprendizagem. Capoeira.

\section{RESUMEN}

El carácter lúdico de la capoeira en favor del ocio activo dentro de la educación escolar tiene como objetivo demostrar las consecuencias del ocio pasivo ejercido por los escolares y la práctica de la capoeira como instrumento de enseñanzaaprendizaje debido a una metodología activa en la que el El sujeto del proceso puede sentirse participante en su propia historia formativa y construir una acción social de manera proactiva. Siendo que discute la práctica del ocio activo en contravención del ocio pasivo que segrega a los sujetos en estudios que limitan sus relaciones sociales.

Palabras clave: Ocio. Aprendizaje Capoeira

\footnotetext{
${ }^{1}$ MARTINS, Reginaldo Neves. Graduado em Filosofia e Educação Física; Pós-Graduado em: Gestão escolar, Ciências da Educação e Metodologia do Ensino de Filosofia; Mestre em Ciência da Educação. E-MAIL regynaldomartins@bol.com.br
} 


\section{INTRODUÇÃO}

Discutir o lazer ativo tem sido uma busca constante na prática da vida docente e das rodas de capoeira dentro e fora da unidade escolar. Por isso a necessidade de discutir com os professores de Educação Física na modalidade escolar especialmente, e de forma geral, com os grupos de capoeira que adentra com sua prática corporal na modalidade luta em todo o sistema educacional brasileiro, neste caso específico, com o professorado de Serra do Ramalho, Estado da Bahia - Brasil. Este artigo busca uma reflexão teórica visando combater a dimensão sedentária do lazer passivo proporcionado pelo uso abusivo dos dispositivos da tecnologia da informação através dos jogos eletrônico. Tendo como objetivo, realizar uma demonstração das consequências do lazer passivo exercitado pelos educando em idade escolar e a prática da capoeira como instrumento de ensino-aprendizagem em virtude de uma metodologia ativa em que o sujeito do processo possa sentir participante de sua própria história formativa e construtora de uma ação social de maneira proativa. Para tal, parte-se da pesquisa bibliográfica com metodologia qualitativa. Primeiramente demostra a capoeira como instrumento da educação em que percorre as fontes históricas e instituições que reconhecem a capoeira e suas contribuições formativas; em seguida as múltiplas dimensões pedagógicas da capoeira com suas variadas possibilidade de aplicabilidade na ação pedagógica; por fim, a capoeira na prática escolar como instrumento sugestivo do lazer ativo em combate ao doentio abuso dos jogos eletrônicos e as consequências do sedentarismo.

\section{A CAPOEIRA COMO INSTRUMENTO DA EDUCAÇÃO}

A educação do século XXI traz em sua essência múltiplas dimensões para atender as demandas vigentes das nova tecnologias e mercado de trabalho. Até as últimas décadas do século $\mathrm{XX}$, ensinava-se para o mercado de trabalho visando uma melhoria na família e consequentemente o desenvolvimento da sociedade como um todo. As empresas pleiteavam funcionários que tivesse habilidade especifica para determinada vaga oferecida. A pessoa que tinha uma formação média, ou seja, antigo segundo grau, já estava apto a assumir boas vagas de 
trabalho com salários razoavelmente bons, o que possibilitava um melhor desenvolvimento de seus filhos no processo formativo e profissional.

As consequências desse processo foram de extrema relevância para o desenvolvimento das novas tecnologias que hoje domina o universo infanto-juvenil, o qual levaram-vos a uma nova demanda educacional desde a educação infantil até o ensino superior. Possuidoras de um status social bem mais elevado, passaram a consumir mais e, em detrimento do mesmo, passaram a ser sujeitos ao lazer passivo de forma exorbitante, trazendo sérios problemas sociais de relação familiar e social. Embora os novos meios tecnológicos deveriam ser utilizados para facilitar a vida das pessoas, seja de forma profissional, familiar e social, trouxe imbuídos de si sérios problemas de sedentarismo e interação social, pois as crianças e adolescentes em idade escolar apoderam-se deste conhecimento encantador, que são os jogos eletrônicos e diversos recursos apresentados pelas redes sociais de comunicação, ausentando-se das brincadeiras lúdicas e de interação social e, consequentemente isolando-se do mundo social.

Essa geração em idade escolar, que apoderam-se dos jogos eletrônicos e das redes socias, em sua maioria, tem dificuldade de se relacionar com o outro, pois vivem interagindo através dos aplicativos e, pessoalmente tem tremendas dificuldades de resolver conflitos e encontrar soluções para seus problemas, pois, é das relações que nos tornamos humanos e, produzimos nossa mais diversificada forma de viver.

O desafio das escolas do século XXI é diversificar o currículo e atender esta nova geração sem excluir do currículo tradicional possibilitando-os novas demandas que possam inseri-los no meio social através de novas técnicas de ensino em que haja a formação pessoal, social e consequentemente a formação para o mercado de trabalho que exige cada vez mais um sujeito robusto de conhecimento humano e técnico-científico para que possa se garantir na nova ordem mundial.

$\mathrm{Na}$ disciplina de Educação Física, através da Base Nacional Comum Curricular - BNCC (2017) em sua décima competência específica diz: experimentar, desfrutar, apreciar e criar diferentes brincadeiras, jogos, danças, ginásticas, esportes, lutas, práticas corporais de aventura e capoeira, valorizando o trabalho coletivo e o protagonismo. 
Nessa perspectiva, compreender a capoeira como jogo, dança, luta, esporte, cultura e patrimônio imaterial da humanidade está entre as perspectivas de ensino que o estudante deve percorrer durante o Ensino Fundamental e em toda a Educação Básica. Habilidades que podem diversificar a prática docente e o interesse da aprendizagem do estudante, pois a musicalidade e a prática da capoeira abrem horizontes de possibilidades.

\begin{abstract}
Relevante observar que apesar da relação capoeira e jogo ter abarcado o menor potencial, as categorias posteriores - dança, luta, esporte e cultura - podem ser condensadas dentro dos pressupostos mais profundos e abrangentes que constituem os preceitos dos jogos pedagógicos. Por seu turno, observando os correspondentes teóricos e práticos, é coerente deduzir que a capoeira se ajusta ao sentido universal e não estrito de jogos. (MARTINS, 2019. p. 96).
\end{abstract}

Todo jogo, por mais simplório que seja, o que não é o caso do jogo da capoeira, traz em sua essência as regras, história e fundamentos pedagógicos que possibilita a recriação, dando assas a criatividade do estudante e do docente. A capoeira aplicada em sala de aula ou em seus arredores da escola implica na interiorização do conteúdo, onde o estudante extrai as habilidades necessárias da comunicação, interação, comunicação na prática de reflexão, análise e aplicação dos movimentos do jogo e das regras de sua utilização para com seu opositor.

Conforme Silva (2017, p. 57) "[...] se esse foi um caminho de aceitação social e saída da marginalidade, com certeza não representou o abandono total de um referencial educativo calcado na oralidade, aprender-fazendo, respeito aos mais antigos, dentre outros". Referindo ao processo de libertação dos escravos e posteriormente com a consolidação da capoeira como uma luta genuinamente brasileira, Silva explica que a Capoeira passa a contribuir com a prática pedagógica através de sua experiência não somente na teoria como também na prática.

A abrangência da capoeira que vai conseguir qualificá-la para assumir o posto de restauradora das funções sociais centradas no teor biopsicossocial. Em última análise, a capoeira corresponde ao revigoramento do seu processo histórico gerador ou, em outras palavras, das suas tradicionais perspectivas e formas. Imbuída de valores educacionais capazes de contribuir com sua dimensão de jogo na formação 
biopsicossocial do indivíduo de forma lúdica e pedagógica nos sistemas de ensino regular. Elkonin (1984, p. 75): "o jogo é uma manifestação social que consiste reconstruir, no todo ou em parte, qualquer fenômeno da vida real devidamente acompanhado do seu verdadeiro propósito prático". Assim sendo, reiteram com a ludicidade a dimensão da aprendizagem a partir da prática da capoeira com sua variante do jogo além das múltiplas técnicas utilizadas pela musicalidade, a dança, a luta e a cultura afro-brasileira nela expressa.

\section{AS MÚLTIPLAS DIMENSÕES PEDAGÓGICAS DA CAPOEIRA}

O lazer tratado neste artigo não restringe apenas ao grupo de uma ocupação aleatória que visa preencher o tempo da pessoa em horas vagas, mas busca ressaltar seu lado crítico como construtor de uma consciência ativa transformadora da realidade sedentário e passiva engendrada pelo sistema social e tecnológico "escravagista".

Já o Lazer ativo possibilita uma nova enunciação das múltiplas vivências, uma conversão das atividades em conhecimento, em expressão criadora e em novos olhares e potencialidades. Neste campo é permitida uma maior convivência social e uma melhor qualidade de vida. Simultaneamente o ser encontra o desejado deleite e o imprescindível repouso. (SANTANA, 2019?)

A escola tem o papel fundamental de propor e estimular aos estudantes a empossar das atividades lúdicas e recreativas que levem-vos a praticarem em vossos tempos livres fora da unidade escolar para que os mesmos encontrem caminhos, estratégias, meios e alternativas de lazer ativo. A pesquisa realizada por Martins (2019) na Escola Nossa Senhora Aparecida da Agrovila 08, Município de Serra do Ramalho, Bahia, os sujeitos pesquisados reafirmam que a capoeira é uma arte com várias dimensões educativas; que ainda é uma expressão cultural brasileira que pode ser compreendida como arte, esporte, cultura popular e música. Sendo que os praticantes também utilizam instrumentos musicais proporcionando bons ritmos. 
A partir do momento que a pessoa pratica capoeira, ela se envolve e descobre as várias faces dessa atividade, porque a capoeira não é só uma forma de luta, ela também é arte, cultua, dança e também esporte, onde o mesmo pode aprender não movimentos, mais também, músicas e o principal de tudo a sua história. (SERESTEIRO, 2018, apud MARTINS, 2019, P. 102).

Como bem referencia Martins (2019), essa polissemia de significados e possibilidades para uma aula, seja ela teórica ou prática de capoeira, aplicada na educação formal, preferencialmente de forma lúdica através do eixo temáticos das lutas na disciplina de Educação Física, enriquecerá o vocabulário, as relações interculturais e sociais no fazer pedagógico e o despertar criativo do educando tornando-o sujeito de seu processo de aprendizagem. Pode-se reafirmar na referida escola Nossa Senhora Aparecida da Agrovila 08, Serra do Ramalho - BA, em que se aplica a Proposta Pedagógica de Educação Física, elaborada por Martins (2018), onde a capoeira entra como um objeto de conhecimento das lutas pela disciplina de Educação Física, que, desde o ano de 2016, a escola tem como projeto extraclasse a prática da capoeira em parceria com a escola e o cumprimento do componente curricular.

Uma aula, aonde o estudante é parte do seu processo de ensinoaprendizagem, possivelmente ele encontra mais sentido e significado, dando the mais sentido na sua vida prática possibilitando a prática de uma atividade física com movimentos ativos e proativos tirando-Ihes as consequências do sedentarismo exacerbado e prejudicial para o desenvolvimento cognitivo e social, o qual prejudica nas relações interpessoais e, em consequência, a saúde física. Reiterando a posição, a capoeira é um espaço dinâmico onde os limites são reconhecidos e o respeito à alteridade é assimilado. A capoeira é um meio didático e pedagógico que pode auxiliar em situações mediadora e é uma via disciplinar que se articula dentro dos moldes educativos.

Enquanto método inclusivo a capoeira oferece uma extensa arena para construção, desempenho e negociação de significados, normas e valores culturais. Como espaço de trocas dinâmicas, ela se torna base de uma crescente conscientização da necessidade de dividir códigos que tornem acessíveis questões sociais mais profundas. Nesse sentido, partindo do princípio que é o desrespeito às diferenças que polarizam e esgarçam o tecido social, as 
respeitabilidades advindas dos códigos compartilhados e respeitados geram um alinhamento que suscitam a prática da inclusão. (MARTINS, 2019, p. 103).

A capoeira é uma verdadeira enciclopédia de conhecimento e possibilidades didáticas e pedagógica, além de apresentar as dimensões da dança, da luta, do jogo, do esporte e da cultura, também é um instrumento de inclusão social, pois tem espaço para todos que dela queiram usufrui, seja com sua instrumentalização, musicalidade ou seus variados movimentos em perspectivas diferentes do sujeito da aprendizagem.

\section{A CAPOEIRA NA PRÁTICA ESCOLAR COMO INSTRUMENTO SUGESTIVO DO LAZER ATIVO}

Segundo Santana (2019?) o Lazer, que vem do latim 'licere' - ser lícito, ser permitido -, é normalmente definido como uma série de atividades que o ser pode praticar em seu tempo livre. Enquanto que a palavra Ativa, remete ao sujeito que pratica a ação de realizar algo. A junção das duas palavras pode nos orientar à prática pedagógica exercitada pelo professor e a ação sofrida pelo educando de aprender através das dimensões didático pedagógica da capoeira em suas variadas dimensões da teoria e da prática da capoeira como currículo da disciplina de Educação Física que leva para a vida pessoal e social do sujeito do conhecimento.

Segundo Martins (2019) "a capoeira é um lugar de abertura onde muitos sentimentos podem ser incorporados sem receio ou limitações. Quer dizer, possui estreitos laços com o acolhimento das diversidades". Isso significa que as dimensões didáticas e pedagógicas que a capoeira traz em si, possibilita ao educando expressar de diversas formas seus sentimentos e simultaneamente acontece o envolvimento do mesmo na prática do ensino e aprendizado manifestado na aula de capoeira. Delineando ainda sobre esta prática, o capoeirista (aluno) mescla com os expectadores, que muitas vezes podem ser seus próprios colegas de classe, seus pais e comunidades que apoiam a prática pedagógica da unidade escolar. Pois na essência da capoeira há o universo do particular e do universal. Particular é a dimensão que o capoeirista quer e busca para si, universal aquilo que 
a capoeira tem a oferecer nas dimensões da dança, da luta, do jogo, do esporte, da musicalidade, da instrumentalidade, etc.

O papel da educação contemporânea é exatamente o de possibilitar competências e auxiliar os educandos a desenvolverem as habilidades necessárias para solucionar os problemas passiveis da vida humana. Expresso na primeira competência da BNCC (2017), "Valorizar e utilizar os conhecimentos historicamente construídos sobre o mundo físico, social, cultural e digital para entender e explicar a realidade, continuar aprendendo e colaborar para a construção de uma sociedade justa, democrática e inclusiva". A capoeira como Patrimônio Histórico Imaterial da Humanidade é um destes conhecimentos historicamente construídos propícios a ser explorado na educação básica de forma integral em que o sujeito da aprendizagem leve para sua prática social e familiar como alternativa de lazer ativo ao tempo que Ihes garanta, ao mesmo tempo, saúde física e mental, pois a capoeira Ihes tirará da cultura massacrante e viciantes dos jogos eletrônicos e lazeres passivos. Sendo assim, encontramos na capoeira a possibilidade de intervenção educativa e uma ferramenta de comunicação, ampliação das diversas linguagens e do conhecimento, consequentemente a compreensão, apreensão e transformação da vida sedentária e pobre em conhecimento social e cultural.

\section{CONSIDERAÇÕES FINAIS}

No presente estudo de cunho bibliográfico em que se buscou compreender melhor e destacar as dimensões didáticas e pedagógica da capoeira em virtude do exercício do fazer educacional em prol da ação social do lazer ativo. Para tanto, partiu-se da compreensão de que a capoeira expressa as dimensões da dança, do jogo, da luta, do esporte, da cultura e do lazer em que permite ao educador e o educando uma vasta gama de possibilidades levando-os a refletir a sua prática pessoal e social no seu mundo em que vive.

Ao observar os reais problemas sociais e a prática educacional através da pesquisa-ação, ficou evidente que as práticas dos jogos eletrônicos e as diversas formas de lazer passivos, como as expressas nas redes sociais de comunicação e televisores é que se busca aqui, assumir a dimensão de uma prática pedagógica através da metodologia ativa em que o sujeito do processo educacional sinta 
participante da construção de seu conhecimento, e que, ao mesmo tempo o tenha na prática de sua vida pessoal e social mudanças de comportamentos que almejam seu pleno desenvolvimento como sujeitos ativos perante a vida social.

\section{REFERENCIAS}

BRASIL, Ministério da Educação. Base Nacional Comum Curricular - Ensino Fundamental. Brasília, 2017 BRASIL. Conselho Nacional de Educação. Resolução CNE/CEB no 3, de 10 de novembro de 1999 - Fixa Diretrizes Nacionais para o funcionamento das escolas indígenas e dá outras providências.

ELKONIN, D. B. Psicologia do jogo. São Paulo: Martins Fontes, 1984.

MARTINS, Reginaldo Neves. Analisar a capoeira como instrumento de empoderamento de adolescentes em situação de risco do Município de Serra do Ramalho, BA. Dissertação de Mestrado pela FICS - Faculdad Interamericana e Ciencias Sociales. Assunção - Paraguaio, p 137. 2019.

MARTINS, Reginaldo Neves. Proposta Pedagógica de Educação Física. Secretária Municipal de Educação, Cultura, Desporto e Lazer. Serra do Ramalho BA. 2018.

SANTANA, Ana Lucia. Lazer. INFOESCOA Disponível em: $<$ www.infoescola.com/sociologia/lazer/>; acessado em: 22 de jan. de 2020.

SILVA, Jean Adriano Barros da. Capoeira: limites e possibilidades-um processo pedagógico criativo a emancipar a cidadania inclusiva. Tese de doutorado pela Universidade do Minho - Instituto de Educação, Campus de Gualtar - Braga Portugal, p. 238. 2017. 